\title{
Analysis of Ganglion Cell Complex in Various Stages of Primary Open Angle Glaucoma
}

\author{
Singh L¹, Bundela RK², Rathore SS ${ }^{3}$, Ahmad L ${ }^{3}$, Lal BB ${ }^{4}$ \\ 1Professor, ${ }^{2}$ Associate Professor, ${ }^{3}$ Resident, ${ }^{4}$ Professor and HOD, \\ Department of Ophthalmology, Era's Lucknow Medical College and Hospital, Lucknow, Uttar Pradesh, INDIA.
}

\begin{abstract}
Introduction: Glaucoma is a major public health problem, causing visual impairment which hampers day to day work. The disability caused by glaucoma is irreversible. It is a 'silent killer' as most of the time, it is asymptomatic up to the very advanced stage and at the time of presentation to the ophthalmologist, the visual loss is often irrecoverable.

Materials and methods: 100 control \& 100 primary open angel glaucoma POAG patients were analysed for Ganglion Cell Complex (GCC). In all the patients clinical examination included assessment of visual acuity, evaluation of refractive status, Intraocular pressure (IOP) measurement, slit-lamp bio microscopy with +90D lens, Gonioscopy, Visual field charting by Humprey Field Analyser (HFA) and scanning with the Cirrus spectral domain - optical coherence tomography (SD-OCT).

Result: Of 100 patients of POAG and equal number of controls analysis revealed that overall Ganglion Cell Complex thickness in POAG cases $(60.40 \pm 19.1 \mu \mathrm{m})$ was less than in controls $(114.70 \pm 18.8 \mu \mathrm{m})$ and this difference is statistically significant $(p<0.001)$
\end{abstract}

\section{INTRODUCTION}

About 60 million persons are estimated to be affected by glaucoma. Of these, an estimated 11.2 million cases are from the Indian subcontinent. ${ }^{1,2}$ It is the world's second leading cause of irreversible blindness ${ }^{1}$. Glaucomatous neuronal death is not limited to changes in the retinal ganglion cell axons, soma, and dendrites, ${ }^{3}$ neurons in the lateral geniculate nucleus ${ }^{4-6}$ and the visual cortex ${ }^{4}$ are also lost. Outcomes of both functional (psychophysical) testing ${ }^{4}$ and histological studies suggest that the pathological process does not discriminate among subsets of retinal ganglion cells. Glial cells also are affected, and it is possible that astrocytes, perhaps activated by raised intraocular pressure or by other mechanisms, alter the environment of the axons and produce a milieu that causes axonal degeneration or that prevents survival of the healthy retinal ganglion cells. 5,6 Glaucomatous optic neuropathy causes progressive death of retinal ganglion cells and their axons. These structural changes precede visual field (VF) defects as measured by standard automated perimetry. The level of intraocular pressure is unquestionably related to the death of retinal ganglion cells and optic nerve fibers in some, if not all, patients with POAG. When pressure increases above physiological levels, the pressure gradient across the lamina cribrosa also increases. As a result, the lamina cribrosa and the retinal ganglion cell axons undergo deformation and mechanical stress. ${ }^{5}$
Conclusion: As the severity of glaucoma increases the overall average GCC thickness becomes progressively thinner. The Ganglion Cell Complex thickness is reduced in POAG.

Keywords: Glaucoma, Ganglion cell layer, OCT.

\section{*Correspondence to:}

Dr. Lubna Ahmad, 15, 4t floor, PM Apartments, behind ELMC\&H, Sarfarazganj, Hardoi Road, Lucknow.

Email: lubbs.ahmad@gmail.com

Article History:
Received: 10-03-2016, Revised: 15-03-2016, Accepted: 17-05-2016
\begin{tabular}{|l|c|}
\hline \multicolumn{2}{|c|}{ Access this article online } \\
\hline $\begin{array}{l}\text { Website: } \\
\text { www.jmrp.com }\end{array}$ & Quick Response code \\
\hline $\begin{array}{l}\text { DOI: } \\
\text { 10.21276/jmrp.2016.2.3.022 }\end{array}$ & \\
\hline
\end{tabular}

In POAG, retinal ganglion cell axon compression can impair trophic factor axonal transport, causing death of the cells by trophic insufficiency. Excessive stimulation of the glutamatergic system, specifically the $\mathrm{N}$-methyl-Daspartate subtypes, has also been proposed to contribute to death of retinal ganglion cells in glaucoma. ${ }^{6-8}$ The response to an initial optic nerve injury in glaucoma also can lead to secondary neurodegeneration among surviving retinal ganglion cells and their fibers.

Optical Coherence Tomography (OCT) can give very accurate parameters for optic nerve head assessment along with the retinal nerve fibre layer analysis ${ }^{6}$ With the help of optical coherence tomography OCT it is possible to detect the loss of ganglion cell complex (GCC). The ganglion cell complex has the maximum density at the macula. Roughly, one lac ganglion cells are found in the human retina and half of this number is centered on the fovea. This anatomic arrangement suggests that a macula scan with GCC analysis could be an early indicator for impending damage caused by POAG. ${ }^{7}$

Optical coherence tomography, a well-accepted tool for glaucoma diagnosis, Spectral domain OCT (SD-OCT) is a recent technique that enables the imaging of ocular structures with higher resolution and faster scan rate compared with the previous version of this technology. 8

In addition to the changes that occur in optic nerve head (ONH) 
and Retinal nerve fibre layer (RNFL), another region that has been proposed to manifest changes in glaucoma is the macula, because more than $50 \%$ of the ganglion cells in the retina are located at macula and the ganglion cell layer is more than onecell-layer thick at the macula. ${ }^{19,20}$ This study was done to analyze the ganglion cell complex among the patients of POAG and to correlate it with the severity of the disease.

\section{MATERIALS AND METHODS}

This was a cross sectional study conducted at Tertiary Medical College in North India. This study was conducted in accordance with the tenets of the Declaration of Helsinki and was approved by an institutional review board.100 control and 100 POAG patients were analysed for Ganglion Cell Complex. Patients with Advanced lens opacities ,prior ocular surgeries, H/O Laser treatments ,refraction - Spherical>5.0 D Cylinder>3.0D, Age related macular degeneration (ARMD), Diabetes Mellitus, hypertension were excluded from the study.

An individual (age $>40$ years) was included in the study as a case of POAG only if he / she met with at least two of the following three criterias: Elevated intraocular pressure (IOP) greater than $21 \mathrm{~mm} \mathrm{Hg}$ without treatment on at least two separate visits; Vertical asymmetry of cup disk ratio $(C D R)>0.2$ between two eyes. High CDR $>0.6$. And the Control Group comprised of Individuals (age $>40$ years) having I.O.P within normal range (11$20 \mathrm{~mm} \mathrm{Hg}$ ) and no glaucoma.

In all the patients clinical examination included assessment of visual acuity by Snellen's chart, evaluation of refractive status by Retinoscopy, IOP measurement by applanation tonometery, slitlamp bio microscopy with +90D lens, Gonioscopy, Visual field charting by Humphrey Field Analyser (HFA).

All included subjects were scanned with the Cirrus SD-OCT (software version 4.0) Carl-Zeiss Meditec Inc., Dublin, CA) by a single operator. Statistical analysis was done using Statistical Package for Social Sciences, version 20.0.

Table 1: Severity Grade of POAG ( $\mathrm{N}=100)$ (Based on visual field by HFA: Hodapp's grading)

\begin{tabular}{lc}
\hline Severity of POAG & $\begin{array}{c}\text { No. of Cases } \\
(\mathbf{N}=100)\end{array}$ \\
\hline Pre perimetric & $12(12.0 \%)$ \\
Mild & $20(20.0 \%)$ \\
Moderate & $56(56.0 \%)$ \\
Severe & $12(12.0 \%)$ \\
Total & $100(100.0)$ \\
\hline
\end{tabular}

(Preperimetric POAG cases did not show any defect/abnormal finding in HFA)

\section{RESULTS}

To analyze the Ganglion Cell Complex among the patients of POAG we evaluated 100 patients of POAG and equal number of controls. Among cases there were 42 males, and 58 females, whereas among controls there were 44 males and 56 females. Majority of controls as well as patients were in the age group of 51-60 years (38 and 43 respectively). The age categories and Gender wise variation in the patients and control groups was not statistically significant.

The data distribution of Ganglion Cell Complex layer thickness analysis in POAG group is given in (Table 2). The severity of glaucoma increases the overall average GCC thickness becomes thinner further and further.

Comparison of Average Ganglion cell complex GCC thickness in control and cases POAG group is given Table 3. The analysis reveals that overall GCC thickness in POAG cases $(60.40 \pm 19.1 \mu \mathrm{m})$ was less than in controls $(114.70 \pm 18.8 \mu \mathrm{m})$ and this difference is statistically highly significant $(p<0.001)$.

Table 2: Data Distribution; GCC Thickness by OCT in POAG Group ( $\mathrm{N}=100)$

\begin{tabular}{|c|c|c|c|c|c|}
\hline \multirow{2}{*}{$\begin{array}{l}\text { MACULAR } \\
\text { AREA }\end{array}$} & \multirow{2}{*}{$\begin{array}{l}\text { Severity grade of } \\
\text { POAG }\end{array}$} & \multicolumn{4}{|c|}{ GCC THICKNESS $(\mu \mathrm{m})$} \\
\hline & & $120 \pm 10$ & $100 \pm 10$ & $80 \pm 10$ & $60 \pm 10$ \\
\hline \multirow[t]{4}{*}{ SUPERIOR } & Preperimetric $(n=12)$ & $1(8.3 \%)$ & $6(50 \%)$ & $4(33.3 \%)$ & $1(8.3 \%)$ \\
\hline & Mild $(n=20)$ & $4(20 \%)$ & $12(60 \%)$ & $2(10 \%)$ & $2(10 \%)$ \\
\hline & Moderate $(n=56)$ & $5(8.9 \%)$ & $12(21.4 \%)$ & $23(41.1 \%)$ & $16(28.5 \%)$ \\
\hline & Severe $(n=12)$ & $0(0 \%)$ & $1(8.3 \%)$ & $5(41.6 \%)$ & $6(50 \%)$ \\
\hline \multirow[t]{4}{*}{ INFERIOR } & Preperimetric $(n=12)$ & $2(16 \%)$ & $6(50 \%)$ & $3(25 \%)$ & $1(8.3 \%)$ \\
\hline & Mild $(n=20)$ & $2(10 \%)$ & $9(45 \%)$ & $8(40 \%)$ & $1(5 \%)$ \\
\hline & Moderate $(n=56)$ & $5(8.9 \%)$ & $14(25 \%)$ & $30(53.5 \%)$ & $7(12.5 \%)$ \\
\hline & Severe $(n=12)$ & $0(0 \%)$ & $2(16.7 \%)$ & $4(33.3 \%)$ & $6(50 \%)$ \\
\hline \multirow[t]{4}{*}{ AVERAGE } & Preperimetric $(n=12)$ & $2(16 \%)$ & $4(33.3 \%)$ & $5(41.6 \%)$ & $1(8.3 \%)$ \\
\hline & Mild $(n=20)$ & $1(5 \%)$ & $7(35 \%)$ & $7(35 \%)$ & $5(25 \%)$ \\
\hline & Moderate $(n=56)$ & $7(12.5 \%)$ & $11(19.6 \%)$ & $15(26.7 \%)$ & $23(41.1 \%)$ \\
\hline & Severe $(n=12)$ & $0(0 \%)$ & $1(8.3 \%)$ & $4(33.3 \%)$ & $7(58.3 \%)$ \\
\hline
\end{tabular}

Table 3: Comparative evaluation GCC thickness $(\mu \mathrm{m})$; Control v/s Case (POAG) group

\begin{tabular}{llll}
\hline MACULAR AREA & CONTROL $(\mathrm{n}=100)$ & POAG $(\mathrm{n}=100)$ & $\mathrm{p}$ value \\
\hline Superior half & $112.47 \pm 18.5$ & $90.28 \pm 18.7$ & 0.001 \\
Inferior half & $115.91 \pm 19.1$ & $78.98 \pm 19.2$ & 0.001 \\
Average & $114.70 \pm 18.8$ & $60.40 \pm 19.1$ & 0.001 \\
\hline
\end{tabular}




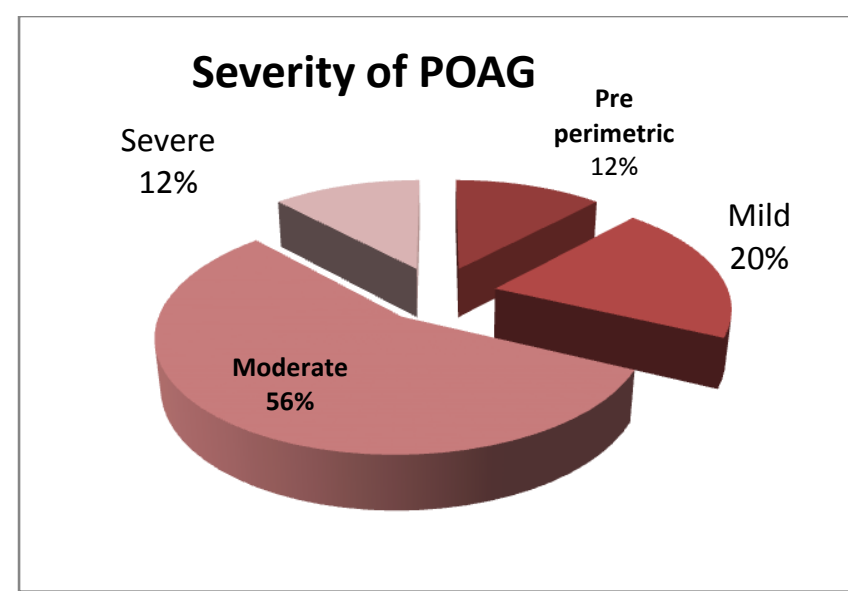

\section{DISCUSSION}

In the present study we aimed to study the changes in ganglion cell complex in primary open angle glaucoma in relation to different grades of its severity and correlate GCC parameters with visual field indices.

The Intraocular pressure variation among POAG cases, ranged from $<20$ to $>50 \mathrm{~mm} \mathrm{Hg}$ with overall mean IOP $31.52 \pm 9.2$ $\mathrm{mmHg}$. In about $32(32 \%)$ cases the ocular pressure was between $40-50 \mathrm{mmHg}$ which was the maximum for the age group.

Severity of Primary Open Angle Glaucoma (POAG) cases was assessed based on visual field analysis by HFA: using Hodapp's grading system (Table 1). The patients were categorized as Mild $20(20.0 \%)$ cases, Moderate $56(56.0 \%)$ cases and Severe 12 $(12.0 \%)$ cases.

The data distribution of Ganglion Cell Complex layer thickness analysis in POAG group is given in (Table 2). In superior quadrant majority patients in preperimetric group $6(50 \%)$ and in mild group $12(60 \%)$ cases were in the range $100 \pm 10 \mu \mathrm{m}$, while moderate glaucoma $23(41.1 \%)$ cases were in the range $80 \pm 10 \mu \mathrm{m}$ and severe $6(50 \%)$ were in the range $60 \pm 10 \mu \mathrm{m}$. In Inferior macular quadrant the GCC thickness in majority preperimetric group, 6 $(50 \%)$ cases and mild group $9(45 \%)$ was in the range $100 \pm 10$ $\mu \mathrm{m}$. In moderate $30(53.5 \%)$ cases GCC thickness was in the range of $80 \pm 10 \mu \mathrm{m}$ and in severe $6(50 \%)$ were in the range $60 \pm 10 \mu \mathrm{m}$. The overall GCC thickness in majority preperimetric and mild glaucoma cases ( $41.6 \%$ and $35 \%$ respectively) was in range of $80 \pm 10 \mu \mathrm{m}$ and was in lowest range of $60 \pm 10 \mu \mathrm{m}$ in maximum moderate and severe glaucoma cases (i.e $41.1 \%$ and $58.3 \%$ respectively).The above observation clearly suggests that as the severity of glaucoma increases the overall average GCC thickness becomes thinner further and further.

Comparison of Average Ganglion cell complex GCC thickness in control and cases POAG group is given Table 3. The analysis reveals that overall GCC thickness in POAG cases $(60.40 \pm 19.1 \mu \mathrm{m})$ in which less than in controls $(114.70 \pm 18.8 \mu \mathrm{m})$ and this difference is statistically highly significant $(p<0.001)$. The comparison of GCC thickness between superior and inferior macular area shows that in the inferior macular area shows that in the inferior area GCC thinning is more marked.

The Ganglion Cell Complex was studied at macular area level and its thickness $(\mu \mathrm{m})$ evaluated in relation to severity of POAG and compared with controls. The GCC thickness in relation to severity of POAG i.e normal with preperimetric is analysed. In controls the mean GCC thickness in the Superior part was $112.47 \pm 18.5 \mu \mathrm{m}$, while in the preperimetric POAG cases in the corresponding area

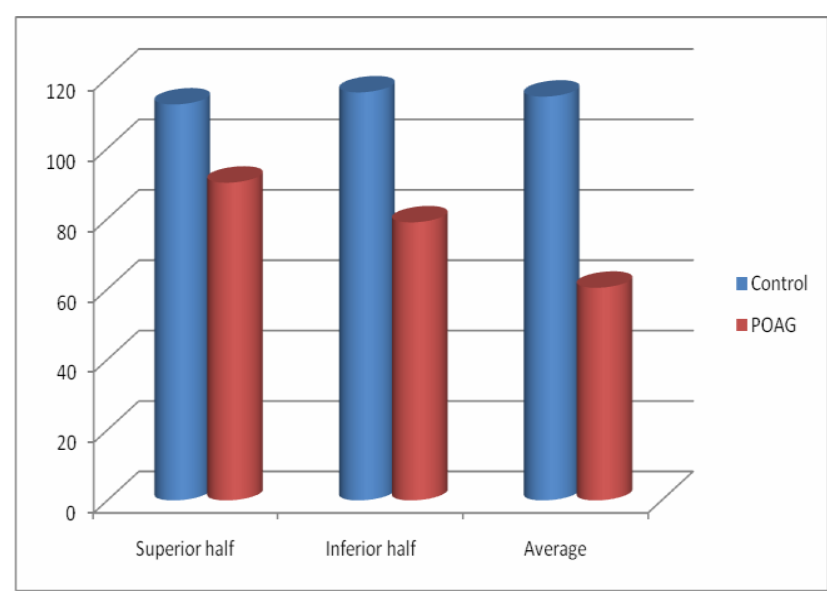

it was $99.47 \pm 18.5 \mu \mathrm{m}$. In the Inferior part the thickness in controls $115.91 \pm 19.1 \mu \mathrm{m}$ as against the mean thickness in the preperimetric POAG cases in the same region was $102.91 \pm 18.9 \mu \mathrm{m}$. The difference between the thicknesses was statistically highly significant $(p<0.001)$. Further the average normal GCC thickness in controls was $114.70 \pm 18.8 \mu \mathrm{m}$ against which the mean average GCC thickness in preperimetric glaucoma cases was $101.2 \pm 19.4 \mu \mathrm{m}$. The difference between the two average thicknesses too was statistically significant.

Avadhesh Oli and D. Joshi21 (2015) studied the ganglion cell complex assessment on (cirrus HD OCT) aid in detection of early glaucoma and they observed that the GCC was 69.19 I in glaucoma patients and it was $71 \mathrm{I}$ in pre-perimetric glaucoma and 99.6 I and 85.16 I in controls respectively. Receiver operating characteristic curve for GCC was 0.83 . GCC can be used as a supplementary tool in picking up cases of pre-perimetric glaucoma as loss is significant in pre-perimetric glaucoma also.

GCC thickness evaluated in relation to increasing severity of POAG and compared with normal i.e in mild glaucoma; moderate glaucoma and severe glaucoma followed the similar pattern as seen in preperimetric glaucoma i.e irrespective of severity grade of glaucoma the average GCC thickness as well as individually in both superior and inferior macular areas it was less as compared to normal controls. The thinning of GCC complex and its difference from normal control group in all the severity grades of glaucoma is statistically significant $(p<0.001)$.

We found that values of GCC were lower both in glaucoma and preperimetric glaucoma patients indicating the importance and superiority of GCC analysis in early diagnosis of glaucoma. Experimental animal models have shown that GCC loss correlates well with visual field defects. ${ }^{16}$ In glaucoma GCC is first to be affected so evaluation of GCC is early indicator of damage GCC can be used as a supplementary tool in picking up cases of preperimetric glaucoma as Ganglion Cell Complex loss is significant in pre-perimetric glaucoma. ${ }^{22}$

Ganekal S ${ }^{23}$ (2012) studied the ganglion cell complex scan in the early prediction of glaucoma and they concluded that the ability to diagnose glaucoma with macular GCC thickness is comparable to that with peripapillary RNFL thickness. Macular GCC thickness measurements may be a good alternative or a complementary measurement to RNFL thickness assessment in the clinical evaluation of glaucoma.

GCC had also shown to be good predictor of damage due to glaucoma. ${ }^{24}$ Some of the studies have tried to differentiate the type of glaucoma based on the nature of GCC loss but other 
studies have failed to establish such a difference. ${ }^{25}$ Periodic GCC measurements can be utilized to detect progression of glaucoma in very nascent stage. ${ }^{26}$ The ability of GCC as compared to RNFL to detect early glaucoma is found to be slightly better in some studies. ${ }^{27}$ Addition of GCC data to RNFL data has been found to enhance the detection of glaucoma in both preperimetric and perimetric groups. ${ }^{28}$ Since this study did not include long term follow up of patients so further studies are required to study the role of serial RNFL and GCC scans in glaucoma progression.

\section{ACKNOWLEDGEMENTS}

We thank the Ethical and Research committee of our Tertiary Medical College and Hospital for their approval and support in this survey. Mr Arun's help with statistics was enormous.

\section{REFERENCES}

1. Resnikoff S, Pascolini D, Etya'ale D, Kocur I, et al. Global data on visual impairment in the year 2002. Bull World Health Organ. 2004; 82: 844-51.

2. Ronnie G, Sathyamangalam R V, and Lingam V. Glaucoma in India: Estimated burden of disease. J Glaucoma.2010;19: 391-7.

3. Weber AJ, Chen H, Hubbard WC, Kaufman PL. Experimental glaucoma and cell size, density, and number in the primate lateral geniculate nucleus. Invest Ophthalmol Vis Sci 2000; 41: 1370-79.

4. Yucel YH, Zhang Q, Gupta N, Kaufman PL, Weinreb RN. Loss of neurons in magnocellular and parvocellular layers of the lateral geniculate nucleus in glaucoma. Arch Ophthalmol 2000; 118: 378-84. 5. Yucel YH, Zhang Q, Weinreb RN, Kaufman PL, Gupta N. Atrophy of relay neurons in magno- and parvocellular layers in the lateral geniculate nucleus in experimental glaucoma. Invest Ophthalmol Vis Sci 2001; 42: 3216-22.

6. Yucel YH, Zhang Q, Weinreb RN, Kaufman PL, Gupta N. Effects of retinal ganglion cell loss on magno-, parvo-, koniocellular pathways in the lateral geniculate nucleus and visual cortex in glaucoma. Prog Retin Eye Res 2003; 22: 465-81.

7. Crawford ML, Harwerth RS, Smith EL 3rd, Mills S, Ewing B. Experimental glaucoma in primates: changes in cytochrome oxidase blobs in V1 cortex. Invest Ophthalmol Vis Sci 2001; 42: 358-64.

8. Sample PA, Bosworth CF, Blumenthal EZ, Girkin C, Weinreb RN. Visual function-specific perimetry for indirect comparison of different ganglion cell populations in glaucoma. Invest Ophthalmol Vis Sci 2000; 41: 1783-90.

9. Pena JD, Agapova O, Gabelt BT, et al. Increased elastin expression in astrocytes of the lamina cribrosa in response to elevated intraocular pressure. Invest Ophthalmol Vis Sci 2001; 42: 2303-14.

10. Wang L, Cioffi GA, Cull G, Dong J, Fortune B. Immunohistologic evidence for retinal glial cell changes in human glaucoma. Invest Ophthalmol Vis Sci 2002; 43: 1088-94.

11. Bellezza AJ, Rintalan CJ, Thompson HW, Downs JC, Hart RT, Burgoyne CF. Deformation of the lamina cribrosa and anterior scleral canal wall in early experimental glaucoma. Invest Ophthalmol Vis Sci 2003; 44: 623-37.

12. Lipton SA. Possible role for memantine in protecting retinal ganglion cells from glaucomatous damage. Surv Ophthalmol 2003; 48(suppl 1): S38-46.

13. Dreyer EB, Zurakowski D, Schumer RA, Podos SM, Lipton SA. Elevated glutamate levels in the vitreous body of humans and monkeys with glaucoma. Arch Ophthalmol 1996; 114: 299-305.

14. Yoles $E$, Schwartz M. Elevation of intraocular glutamate levels in rats with partial lesion of the optic nerve. Arch Ophthalmol 1998; 116 : 906-10.
15. Ramakrishnan R, Mittal S, Ambatkar S, Kader MA. Retinal nerve fibre layer thickness measurements in normal Indian population by optical coherence tomography. Indian J Ophthalmol 2006;54:11-5.

16. Harwerth RS, Carter-Dawson L, Shen F, et al. Ganglion cell losses underlying visual field defects from glaucoma. Investigative Ophthalmology and Visual Science.1999; 40: 2242-2250.

17. Nassif N, Cense B, Park B, et al. In vivo high-resolution video-rate spectral-domain optical coherence tomography of the human retina and optic nerve. Opt Express. $2004 ; 12: 367-376$.

18. Wojtkowski M, Srinivasan V, Ko T, Fujimoto J, Kowalczyk A, Duker J. Ultrahigh-resolution, high-speed, Fourier domain optical coherence tomography and methods for dispersion compensation. Opt Express. 2004;12: 2404-2422.

19. Zeimer R, Asrani S, Zou S, Quigley H, Jampel H. Quantitative detection of glaucomatous damage at the posterior pole by retinal thickness mapping. A pilot study.Ophthalmology. 1998;105:224-231.

20. Curcio CA, Allen KA. Topography of ganglion cells in human retina. J CompNeurol.1990;300:5-25.

21. Oli $A$ and Joshi D. Can ganglion cell complex assessment on cirrus HD OCT aid in detection of early glaucoma? Saudi Journal of Ophthalmology, 2015;29:201-204.

22. le Pv TO, Chopra V, Francis BA, Ragab O, Varma R, Huang D. Regional correlation among ganglion cell complex, nerve fiber layer, and visual field loss in glaucoma. Invest Ophthalmol Vis Sci2013;54:4287-95.

23. Ganekal S .Ganglion cell complex scan in the early prediction of glaucoma. Nepal J Ophthalmol 2012; 4 (8) : 236-241.

24. Firat PG, Doganay S, Demirel EE, Colak C. Comparison of ganglion cell and retinal nerve fiber layer thickness in primary openangle glaucoma and normal tension glaucoma with spectral-domain OCT. Graefes Arch Clin Exp Ophthalmol 2013;251:831-8.

25. Kim NR, Hong S, Kim JH, Rho SS, Seong GJ, Kim CY. Comparison of macular ganglion cell complex thickness by fourierdomain oct in normal tension glaucoma and primary open-angle glaucoma. J Glaucoma 2013;22:133-9.

26. Moura AL, Raza AS, Lazow MA, De Moraes CG, Hood DC. Retinal ganglion cell and inner plexiform layer thickness measurements in regions of severe visual field sensitivity loss in patients with glaucoma. Eye (Lond) 2012; 26:1188-93.

27. Azusa Akashi AK, Makoto Nakamura, Masashi Fujihara, Yuko Negi, Akira Negi.Comparative assessment for the ability of cirrus, RTVue and 3D OCT to diagnose glaucoma. Invest Ophthalmol Vis Sci 2013;54:4478-84.

28. Sung MS, Yoon JH, Park SW. Diagnostic validity of macular ganglion cell- inner plexiform layer thickness deviation map algorithm using cirrus HD-OCT in preperimetric and early glaucoma. J Glaucoma 2014;23(8):e144-51.

Source of Support: Nil.

Conflict of Interest: None Declared.

Copyright: (c) the author(s) and publisher. IJMRP is an official publication of Ibn Sina Academy of Medieval Medicine \& Sciences, registered in 2001 under Indian Trusts Act, 1882.

This is an open access article distributed under the terms of the Creative Commons Attribution Non-commercial License, which permits unrestricted non-commercial use, distribution, and reproduction in any medium, provided the original work is properly cited.

Cite this article as: Singh L, Bundela RK, Rathore SS, Ahmad L, Lal BB. Analysis of Ganglion Cell Complex in Various Stages of Primary Open Angle Glaucoma . Int J Med Res Prof. 2016; 2(3):95-98. 